\title{
Penggunaan Metode Nadir Compromise Programming dalam Menyelesaikan Permasalahan Multi Objektif
}

\section{Rika Yepti Indriani*}

Prodi Matematika, Fakultas Matematika dan Ilmu Pengetahuan Alam, Universitas Islam Bandung, Indonesia.

*rikaindriani189@gmail.com

\begin{abstract}
Multiobjective problems are an optimization problem that has two or more purpose functions. The nadir compromise programming (NCP) method is one that can be used to solve multiobjective problems. To solve that the problem, the NCP solves the problem be based nadir value from each objective. One of problems that can be solved by NCP method is the optimization of the stock portfolio. With the invest, there are some goals taken into consideration for obtaining the optimal portfolio. For the goal of investing in the optimum stock portfolio selection to be reached, in this study will formulate three objectives considered that is optimized risk, maximizing expected return, and minimizing investment capital. The goal of the study is to figure out the use of the NCP method in the solved multi objective optimization problem with the stock portfolio based to data of closing price from 2015 to 2018. In the research analysed of six shares registered in the Indonesia stock exchange in sector property, real estate and building construction. From the optimization resulted 2 shares were selected with the optimal risk coefficient value of 1 , expected return with a maximum of 0.01037969 , and minimum of investment capital 390.
\end{abstract}

Keywords: Multi-objective Optimitation, NCP, Stock Portfolio.

Abstrak. Permasalahan multi objektif ialah permasalahan optimasi yang memiliki dua atau lebih fungsi tujuan. Metode Nadir Compromise Programming (NCP) merupakan salah satu metode yang dapat digunakan untuk menyelesaikan permasalahan multi objektif. Untuk menyelesaikan permasalahan tersebut, NCP menyelesaikan permasalahan berdasarkan nilai nadir dari masingmasing tujuan yang ada. Salah satu permasalahan yang dapat diselesaikan dengan metode NCP adalah permasalahan optimasi portofolio saham. Dalam berinvestasi, terdapat beberapa tujuan yang dipertimbangkan untuk memperoleh portofolio yang optimal. Agar tujuan dalam berinvestasi tercapai dalam pemilihan portofolio saham yang optimal maka dalam penelitian ini dirumuskan tiga fungsi tujuan yang dipertimbangkan yaitu mengoptimalkan risiko, memaksimalkan expected return, dan meminimalkan modal investasi. Tujuan penelitian ini adalah untuk mengetahui penggunaan metode NCP dalam menyelesaikan permasalahan optimasi multi objektif pada portofolio saham dari data closing price mulai dari tahun 2015 sampai 2018. Pada penelitian dianalisis 6 saham yang terdaftar di Bursa Efek Indonesia pada sektor property, realestate and building construction. Dari hasil optimasi dihasilkan 2 saham terpilih dengan nilai koefisien risiko optimal sebesar 1, expected return maksimal sebesar 0.01037969, dan modal investasi minimal 390.

Kata Kunci: Optimasi Multi Objektif, NCP, Portofolio Saham. 


\section{A. Pendahuluan}

Pemrograman terdiri dari beberapa macam, yaitu pemrograman statis dan dinamis. Dilihat dari karakteristik data, terdapat data yang crisp dan ada pula data yang samar (misal program linear dengan data fuzzy) (Fauziah, 2016). Permasalahan optimasi berdasarkan jumlah tujuannya dapat dibedakan menjadi dua yaitu single-objective problem dan multiobjective problem. Permasalahan multi objektif atau disebut juga multiobjective problem ialah permasalahan yang terdiri dari berbagai fungsi tujuan guna menyelesaikan sebuah permasalahan yang kompleks. Dalam dunia nyata banyak masalah yang mempunyai banyak tujuan, seringkali terjadi konflik diantara fungsi tujuan tersebut yaitu perbaikan terhadap satu fungsi tujuan akan berpengaruh buruk terhadap fungsi tujuan yang lain sehingga solusi yang diperoleh berupa solusi kompromi (compromise solution) (Fajar dan Badruzzaman 2005). Pada permasalahan multi objektif biasa dilakukan dengan menggunakan solusi kompromi diantaranya dengan metode Vikor (Suhaedi, 2009). Selain menggunakan metode Vikor, terdapat metode lain yang dapat menyelesaikan permasalahan multi objektif yaitu metode Nadir Compromise Programming (NCP). Metode NCP dirumuskan atas dasar nilai-nilai nadir atau nilai anti ideal dari masing-masing tujuan sehingga akan dicari solusi optimal dari sebuah permasalahan multi objektif dari nilai nadirnya (Amiri, et al, 2011). Terdapat banyak per-masalahan multi objektif yang dapat diselesaikan menggunakan metode NCP, salah satunya dalam menentukan portofolio yang optimal dari kumpulan saham.

Portofolio yang terbaik adalah portofolio yang optimal. Portofolio saham merupakan cara yang dilakukan oleh investor dalam mengalokasikan sejumlah dana tertentu untuk memperoleh keuntungan yang optimal (Fahmi, 2015). Banyaknya jenis saham menyebabkan investor sulit dalam memilih saham-saham yang terbaik. Para investor perlu memaksimalkan tingkat pengembalian (return) untuk mendapatkan keuntungan yang maksimal dan akan mengharapkan keuntungan yang maksimal di kemudian hari terhadap sejumlah dana yang telah diinvestasikannya. Sehingga dapat dirumuskan fungsi tujuan yang ingin dicapai investor yaitu dengan memaksimalkan return yang di-harapkan (expected return). Investor tentu menginginkan nilai harapan tingkat pengembalian semaksimum mungkin dengan megurangi risiko. Agar tetap memperoleh return yang diharapkan dengan risiko sesuai keinginan maka dirumuskan fungsi tujuan lainnya yaitu dengan mengoptimalkan risiko investasi. Selain memperhatikan return dan risiko, investor juga perlu mem-perhatikan modal untuk investasinya. Perlu diminimalkan modal investasi agar tidak terjadi kerugian. Sehingga dapat dirumuskan fungsi tujuan lainnya lagi yaitu dengan meminimalkan modal investasi.

Dalam permasalahan pemilihan portofolio dianalisa bagaimana meng-alokasikan modal agar memperoleh keuntungan maksimal dengan besar risiko yang diinginkan. Sehingga jika dirumuskan dalam sebuah model optimasi akan terdapat tiga fungsi tujuan yang dipertimbangkan dalam membentuk portofolio saham yang optimal yaitu mengoptimalkan risiko, memaksimalkan expected return dan meminimalkan modal investasi.

Berdasarkan latar belakang yang telah diuraikan diatas maka rumusan masalah yang akan dibahas yaitu bagaimana penggunaan metode NCP dalam menyelesaikan permasalahan optimasi multi objektif pada portofolio saham dengan tujuan untuk mengetahui penggunaan metode NCP dalam menyelesaikan permasalahan optimasi multi objektif pada portofolio saham.

\section{B. Metodologi Penelitian}

\section{Metode NCP}

Metode NCP merupakan pengembangan dari metode Compromise Programming (CP), dimana solusi optimal metode CP diperoleh dari nilai ideal fungsi tujuan. Metode NCP ini pertama kali dipublikasikan pada tahun 2011 oleh Amiri et al. Metode NCP ialah salah satu metode yang dapat digunakan untuk menyelesaikan masalah multiobjektif dengan menggunakan model optimasi berdasarkan nilai nadir yang diperoleh dari kemungkinan solusi terburuk dari fungsi tujuan (Noviyanto, 2016).

NCP meminimalkan jarak antara fungsi tujuan dan nilai nadirnya menggunakan nilai nadir yaitu kebalikan dari nilai ideal, berikut model optimasi NCP dengan fungsi untuk mengoptimalkan fungsi tujuan ke- $i\left(f_{i}\right)$, meminimalkan fungsi tujuan ke- $j\left(f_{j}\right)$, dan 
memaksimalkan fungsi tujuan ke-k $\left(f_{k}\right)$ secara umum dapat dirumuskan menjadi (Amiri, et al, 2011):

$$
\operatorname{Min}\left\{\sum_{i=1}^{I} w_{i}\left(\delta_{i}^{+}+\delta_{i}^{-}\right)^{P}+\sum_{j=1}^{J} w_{j}\left(-\delta_{j}^{-}\right)^{P}+\sum_{k=1}^{K} w_{k}\left(-\delta_{k}^{+}\right)^{P}\right\}^{\frac{1}{P}}
$$

dengan kendala,

$$
\begin{gathered}
f_{i}-\delta_{i}^{+}=f_{(i)} \\
f_{i}+\delta_{i}^{-}=f_{(i)} \\
f_{j}+\delta_{j}^{-}=f_{j *} \\
f_{k}-\delta_{k}^{+}=f_{k *} \\
f_{(i)} \in \mathbb{R} \\
\delta_{i}^{+}, \delta_{i}^{-}, \delta_{j}^{-}, \delta_{k}^{+} \geq 0 \\
i=1,2, \ldots, I ; j=1,2, \ldots, J ; k=1,2, \ldots, K
\end{gathered}
$$

dimana,

$w_{i}$ : bobot fungsi tujuan ke- $i$

$w_{j}$ : bobot fungsi tujuan ke- $j$

$w_{k}$ : bobot fungsi tujuan ke- $k$

$\delta_{i}^{+}$: deviasi positif fungsi tujuan ke- $i$

$\delta_{i}^{-}$: deviasi negatif fungsi tujuan ke- $i$

$\delta_{j}^{-}$: deviasi negatif fungsi tujuan ke- $j$

$\delta_{k}^{+}$: deviasi positif fungsi tujuan ke- $k$

$f_{j *}$ : nilai nadir dari fungsi tujuan ke- $j$

$f_{k *}:$ nilai nadir dari fungsi tujuan ke- $k$

$\mathrm{P}$ : parameter

I, J, K : banyakmya masing-masing fungsi tujuan.

\section{Return dan Expected Return}

Return merupakan keuntungan yang diperoleh dari investasi. Berikut rumus return (Husnan, 2003):

dimana:

$$
R_{i j}=\frac{S_{j}-S_{j-1}}{S_{j-1}}
$$

$R_{i j}=$ Tingkat pengembalian (return) saham saat ke $-j$

$S_{j} \quad=$ Harga saham pada saat periode ke $-j$

$S_{j-1}=$ Harga saham pada saat periode sebelumnya $(j-1)$

Expected Return merupakan keuntungan yang diharapkan oleh investor di kemudian hari dari investasinya. Rumus dari Expected Return adalah (Husnan, 2003):

dimana:

$$
E\left(R_{i}\right)=\frac{\sum_{j=1}^{N} R_{i j}}{N}
$$

$E\left(R_{i}\right)=$ Return yang diharapkan pada saham $i$

$R_{i j}=$ Return saham $i$ pada saat ke $-j$ dan seterusnya

$N=$ Banyaknya periode pengamatan

\section{Koefisien Risiko}

Menghitung risiko investasi tiap perusahaan dimaksudkan untuk me-ngetahui seberapa jauh kemungkinan nilai yang akan kita peroleh me-nyimpang dari nilai yang diharapkan. Risiko berpengaruh positif terhadap return (Nurdiawan, 2015). Perhitungan dapat dilakukan dengan 
mencari koefisien risiko. Untuk mencari koefisien risiko dapat di-gunakan rumus sebagai berikut (Reilly dan Brown, 2011):

$$
\beta_{i}=\frac{\operatorname{Cov}\left(R_{i}, R_{m}\right)}{\sigma_{m}^{2}}=\frac{\sum_{j=1}^{N}\left(R_{i j}-E\left(R_{i}\right)\right)\left(R_{m j}-E\left(R_{m}\right)\right)}{\sum_{j=1}^{N}\left(R_{m j}-E\left(R_{m}\right)\right)^{2}}
$$

dimana:

$$
\begin{array}{ll}
\operatorname{Cov}\left(R_{i}, R_{m}\right) & =\text { nilai kovarian return saham- pasar } \\
\sigma_{m}^{2} & =\text { Nilai varians dari pasar } \\
R_{i j} & =\text { Return saham } i \text { pada saat ke- } j \text { dan seterusnya } \\
E\left(R_{i}\right) & =\text { Return yang diharapkan saham } i \\
R_{m j} & =\text { Return dari indeks pasar pada saat ke- } j \text { dan seterusnya } \\
E\left(R_{m}\right) & =\text { Return yang diharapkan dari indeks pasar }
\end{array}
$$

\section{Hasil Penelitian dan Pembahasan}

\section{Deskripsi Data}

Data yang digunakan meliputi data closing price dari enam saham mulai dari tahun 2015 sampai 2018, berupa data saham bulanan perusahaan yang terdaftar di Bursa Efek Indonesia. Keenam saham tersebut perusahaan pada sektor property, realestate and building construction, yaitu PT. Fortune Mate Indonesia Tbk (FMII), PT. Pudjiadi Prestige Tbk (PUDP), PT. Pakuwon Jati Tbk (PWON), PT. Suryamas Dutamakmur Tbk (SMDM), PT. Sitara Propertindo Tbk (TARA), dan PT. Waskita Karya (Persero) Tbk (WSKT).

\section{Perhitungan Return dan Expected Return}

Perhitungan return ini untuk mengetahui suatu saham untung atau rugi pada periode tertentu, dapat dihitung nilai return dengan menggunakan persamaan (2). Setelah diketahui return saham masing-masing periode maka dapat dihitung expected return dari suatu saham.

Tabel 1. Nilai Expected Return Masing-masing Saham (dalam desimal)

\begin{tabular}{|c|c|c|}
\hline No. & Saham & $E\left(R_{i}\right)$ \\
\hline 1. & FMII & 0.023522306 \\
\hline 2. & PUDP & 0.005795997 \\
\hline 3. & PWON & 0.009464881 \\
\hline 4. & SMDM & 0.011872268 \\
\hline 5. & TARA & 0.015419265 \\
\hline 6. & WSKT & 0.008055248 \\
\hline
\end{tabular}

Tabel 1 merupakan hasil yang diperoleh dari perhitungan nilai expected return dari masing-masing saham yang didapatkan dengan menggunakan persamaan (3).

\section{Perhitungan Koefisien Risiko}

Sebelum menghitung koefisien risiko masing-masing saham, terlebih dahulu dihitung return pasar. Untuk dapat menghitung nilai return pasar, dengan menggunakan indeks harga saham gabungan (IHSG). Sedangkan koefisien risiko didapatkan dengan membandingkan kovarian return saham-pasar dengan varians dari pasar.

Berikut hasil perhitungan koefisien risiko yang diperoleh untuk masing-masing saham: 
Tabel 2. Nilai Koefisien Risiko Masing-masing Saham

\begin{tabular}{|c|c|c|}
\hline No. & Saham & $\beta_{i}$ \\
\hline 1. & FMII & 0.807142441 \\
\hline 2. & PUDP & 0.54339038 \\
\hline 3. & PWON & 1.579809 \\
\hline 4. & SMDM & 0.056303 \\
\hline 5. & TARA & 0.328527 \\
\hline 6. & WSKT & 1.331914 \\
\hline
\end{tabular}

Tabel 2 merupakan hasil nilai koefisien resiko masing-masing saham yang didapatkan dengan menggunakan persamaan (4).

\section{Perumusan Fungsi Tujuan dan Fungsi Kendala}

Model optimasi portofolio pada penelitian ini terdiri dari tiga aspek yaitu risiko, expected return dan modal investasi. Sedangkan variabel keputusannya yaitu mendapatkan proporsi dana yang diinvestasikan pada masing-masing saham dalam portofolio tersebut. Pendefinisian variabel keputusannya adalah sebagai berikut:

$x_{1}$ : proporsi dana yang diinvestasikan pada saham PT. Fortune Mate Indonesia Tbk.

$x_{2}$ : proporsi dana yang diinvestasikan pada saham PT. Pudjiadi Prestige Tbk.

$x_{3}$ : proporsi dana yang diinvestasikan pada saham PT. Pakuwon Jati Tbk.

$x_{4}$ : proporsi dana yang diinvestasikan pada saham PT. Suryamas Dutamakmur Tbk.

$x_{5}$ : proporsi dana yang diinvestasikan pada saham PT. Sitara Propertindo Tbk.

$x_{6}$ : proporsi dana yang diinvestasikan pada saham PT. Waskita Karya (Persero) Tbk.

Untuk perumusan fungsi tujuan adalah sebagai berikut:

1. Fungsi tujuan mengoptimalkan risiko

$$
\text { opt } f_{1}=\sum_{i=1}^{6} \beta_{i} x_{i}
$$

Dengan $f_{1}$ adalah fungsi tujuan ke-1, $\beta_{i}$ adalah koefisien risiko saham $i$ dan $x_{i}$ adalah proporsi dana saham $i$. Untuk $i=1,2, \ldots, 6$.

2. Fungsi tujuan memaksimalkan expected return

$$
\operatorname{Max} f_{2}=\sum_{i=1}^{6} E\left(R_{i}\right) x_{i}
$$

Dengan $f_{2}$ adalah fungsi tujuan ke-2, $E\left(R_{i}\right)$ adalah expected return saham $i$ dan $x_{i}$ adalah proporsi dana saham $i$. Untuk $i=1,2, \ldots, 6$.

3. Fungsi tujuan meminimalkan modal investasi

$$
\operatorname{Min} f_{3}=\sum_{i=1}^{6} M_{i} x_{i}
$$

Dengan $f_{3}$ adalah fungsi tujuan ke-3, $M_{i}$ adalah modal investasi saham $i$ dan $x_{i}$ adalah proporsi dana saham $i$. Untuk $i=1,2, \ldots, 6$.

$M_{i}$ diperolehrata-rata closing price saham dari tahun 2015-2018. Pada tabel 3 disajikan data untuk $M_{i}$ : 
Tabel 3. Data rata-rata Closing Price untuk masing-masing Saham

\begin{tabular}{|c|c|c|}
\hline No. & Saham & $\begin{array}{c}M_{i} \\
\text { (Rupiah) }\end{array}$ \\
\hline 1. & FMII & 565 \\
\hline 2. & PUDP & 424 \\
\hline 3. & PWON & 561 \\
\hline 4. & SMDM & 111 \\
\hline 5. & TARA & 678 \\
\hline 6. & WSKT & 2106 \\
\hline
\end{tabular}
berikut:

Dalam memenuhi tujuan optimasi portofolio terdapat beberapa kendala yaitu sebagai

1. Fungsi kendala jumlah proporsi dana yang diinvestasikan

$$
\sum_{i=1}^{6} x_{i}=1
$$

2. Fungsi kendala batas atas dan bawah dana yang diinvestasikan

$$
0 \leq x_{i} \leq 0,7, \quad i=1,2,3, \ldots, 6
$$

\section{Nilai Nadir Expected Return dan Modal Investasi}

Untuk portofolio yang terdiri dari 6 saham, nilai nadir dari fungsi tujuan memaksimalkan expected return dapat dirumuskan sebagai berikut:

dengan kendala,

$$
\begin{aligned}
& \text { Min } 0.023522306 x_{1}+0.005795997 x_{2} \\
& +0.009464881 x_{3}+0.011872268 x_{4} \\
& +0.015419265 x_{5}+0.008055248 x_{6}
\end{aligned}
$$

$$
\begin{aligned}
& x_{1}+x_{2}+x_{3}+x_{4}+x_{5}+x_{6}=1 \\
& 0 \leq x_{i} \leq 0,7, \quad i=1,2,3, \ldots, 6
\end{aligned}
$$

Dengan $f_{2 *}$ adalah nilai nadir expected return keenam saham yang dibentuk pada portofolio, maka dengan menyelesaikan model di atas menggunakan LINGO 18 didapatkan $f_{2 *}=0.00647377$

Sedangkan untukportofolio yang terdiri dari 6 saham, nilai nadir dari fungsi tujuan meminimalkan modal investasidapat dirumuskan sebagai berikut:

dengan kendala,

$$
\begin{gathered}
\operatorname{Max} 565 x_{1}+424 x_{2}+561 x_{3} \\
+111 x_{4}+678 x_{5}+2106 x_{6}
\end{gathered}
$$

$$
\begin{gathered}
x_{1}+x_{2}+x_{3}+x_{4}+x_{5}+x_{6}=1 \\
0 \leq x_{i} \leq 0,7, \quad i=1,2,3, \ldots, 6
\end{gathered}
$$

Dengan $f_{3 *}$ adalah nilai nadir modal investasi keenam saham yang dibentuk pada portofolio, maka dengan menyelesaikan model di atas menggunakan LINGO 18 didapatkan $f_{3 *}=1677.6$.

\section{Perhitungan Proporsi Dana dengan Metode NCP}

Pada model NCP ini, bobot masing-masing fungsi tujuan ke- $k\left(\left(W_{k}\right), k=1,2,3\right)$ dianggap sama untuk masing-masing fungsi tujuan dengan jumlah total bobot fungsi tujuan sama dengan 1. Maka masing-masing fungsi tujuan memiliki bobot $\frac{1}{3}$ dengan rincian $\left(W_{1}\right)=\frac{1}{3}$ untuk bobot fungsi tujuan ke-1 yaitu expected return, $\left(W_{2}\right)=\frac{1}{3}$ untuk bobot fungsi tujuan ke-2 yaitu risiko, $\left(W_{3}\right)=\frac{1}{3}$ untuk bobot fungsi tujuan ke-3 yaitu modal investasi. Sedangkan untuk nilai parameter diasumsikan $P=1$. Sehingga diperoleh model NCP untuk masalah pemilihan portofolio berdasarkan persamaan (1) adalah sebagai berikut: 
88 | Rika Yepti Indriani, et al.

$$
\begin{gathered}
\operatorname{Min}\left\{\frac{1}{3}\left(\delta_{1}^{+}+\delta_{1}^{-}\right)+\frac{1}{3}\left(-\delta_{2}^{+}\right)+\frac{1}{3}\left(-\delta_{3}^{-}\right)\right\} \\
\operatorname{Min}\left\{\frac{1}{3}\left(\delta_{1}^{+}\right)+\frac{1}{3}\left(\delta_{1}^{-}\right)+\frac{1}{3}\left(-\delta_{2}^{+}\right)+\frac{1}{3}\left(-\delta_{3}^{-}\right)\right\}
\end{gathered}
$$

dengan kendala,

$$
\begin{gathered}
f_{1}-\delta_{1}^{+}=1 \\
f_{1}+\delta_{1}^{-}=1 \\
f_{2}-\delta_{2}^{+}=f_{2 *} \\
f_{3}+\delta_{3}^{-}=f_{3 *} \\
x_{1}+x_{2}+x_{3}+x_{4}+x_{5}+x_{6}=1 \\
0 \leq x_{i} \leq 0,7 ; i=1,, 2, \ldots, 6 \\
\delta_{k}^{+} \geq 0, \delta_{k}^{-} \geq 0, \quad k=1,2,3
\end{gathered}
$$

Setelah dilakukan perhitungan nilai nadir dari fungsi tujuan dan model NCP dibentuk, selanjutnya adalah menentukan variabel outputnya yaitu menentukan proporsi dana yang diinvestasikan untuk masing-masing saham. Rumusan yang digunaan untuk mencari proporsi dana berdasarkan nilai nadir adalah sebagai berikut:

$$
\operatorname{Min} \frac{1}{3}\left(\delta_{1}^{+}\right)+\frac{1}{3}\left(\delta_{1}^{-}\right)-\frac{1}{3}\left(\delta_{2}^{+}\right)-\frac{1}{3}\left(\delta_{3}^{-}\right)
$$

dengan kendala,

$$
\begin{gathered}
\sum_{i=1}^{6} \beta_{i} x_{i}-\delta_{2}^{+}=1 \\
\sum_{i=1}^{6} \beta_{i} x_{i}+\delta_{2}^{-}=1 \\
\sum_{i=1}^{6} E\left(R_{i}\right) x_{i}-\delta_{2}^{+}=0.00647377 \\
\sum_{i=1}^{6} M_{i} x_{i}+\delta_{3}^{-}=1677.6 \\
x_{1}+x_{2}+x_{3}+x_{4}+x_{5}+x_{6}=1 \\
0 \leq x_{i} \leq 0,7 ; i=1,, 2, \ldots, 6 \\
\delta_{k}^{+} \geq 0, \delta_{k}^{-} \geq 0, \quad k=1,2,3
\end{gathered}
$$

Selanjutnya dengan menyelesai-kan model NCP tersebut menggunakan LINGO 18 , maka didapatkan hasil proporsi dana untuk masing-masing saham yang disajikan dalam tabel 4 :

Tabel 4. Proporsi Dana dari Metode NCP

\begin{tabular}{|c|c|}
\hline$x_{i}$ & Proporsi Dana \\
\hline$x_{1}$ & 0 \\
\hline$x_{2}$ & 0 \\
\hline$x_{3}$ & 0.62 \\
\hline$x_{4}$ & 0.38 \\
\hline$x_{5}$ & 0 \\
\hline$x_{6}$ & 0 \\
\hline
\end{tabular}


Sehingga terpilih variabel $x_{3}$ dan $x_{4}$ sebagai saham yang terbaik dalam pembentukan portofolio saham yang optimal. Dimana diperoleh proporsi dana dari metode NCP yaitu untuk $x_{3}$ adalah saham PT. Pakuwon Jati Tbk (PWON) sebesar 0.62 dan untuk $x_{4}$ adalah saham PT. Suryamas Dutamakmur Tbk sebesar 0.38.

Dari hasil proporsi dana saham-saham terpilih untuk membentuk portofolio yang optimal, maka dapat dihitung nilai-nilai koefisien risiko, expected return, dan modal investasi yang terbentuk dari 2 saham terpilih yaitu saham PWON dan SMDM.

Untuk menghitung nilai risiko:

$$
\begin{aligned}
f_{1} & =\left(x_{1} \times \beta_{1}\right)+\left(x_{2} \times \beta_{2}\right)+\left(x_{3} \times \beta_{3}\right)+\left(x_{4} \times \beta_{4}\right)+\left(x_{5} \times \beta_{5}\right)+\left(x_{6} \times \beta_{6}\right) \\
f_{1} & =(0 \times 0.807142441)+(0 \times 0.54339038)+(0.62 \times 1.579809)+(0.38 \times \\
0.056303) & +(0 \times 1.331914) \\
f_{1} & =1
\end{aligned}
$$

Untuk menghitung expected return:

$$
f_{2}=\left(x_{1} \times E\left(R_{1}\right)\right)+\left(x_{2} \times E\left(R_{2}\right)\right)+\left(x_{3} \times E\left(R_{3}\right)\right)+\left(x_{4} \times E\left(R_{4}\right)\right)+\left(x_{5} \times\right.
$$
$\left.E\left(R_{5}\right)\right)+\left(x_{6} \times E\left(R_{6}\right)\right)$

$$
f_{2}=(0 \times 0.023522306)+(0 \times 0.005795997)+(0.62 \times 0.009464881)+
$$

$(0.38 \times 0.011872268)+(0 \times 0.015419265)+(0 \times 0.008055248)$

$f_{2}=0.01037969$

Untuk menghitung modal investasi:

2106)

$f_{3}=\left(x_{1} \times M_{1}\right)+\left(x_{2} \times M_{2}\right)+\left(x_{3} \times M_{3}\right)+\left(x_{4} \times M_{4}\right)+\left(x_{5} \times M_{5}\right)+\left(x_{6} \times M_{6}\right)$

$f_{3}=(0 \times 565)+(0 \times 424)+(0.62 \times 561)+(0.38 \times 111)+(0 \times 678)+(0 \times$

$f_{3}=390$

Hasil optimasi untuk pemilihan portofolio dengan menggunakan metode NCP diperoleh nilai koefisien risiko optimal sebesar 1 , expected return maksimal sebesar $1 \%$, dan modal investasi minimal Rp.390,-.

Jadi dari hasil optimasi 6 saham pada tahun 2015 sampai 2018 dengan metode NCP diperoleh proporsi dana untuk saham yang terbaik untuk membentuk protofolio optimal adalah sebagai berikut:

Tabel 5. Saham Optimal

\begin{tabular}{|l|}
\hline Saham Optimal \\
\hline 1. \\
\hline 2.
\end{tabular}

Tabel 5 merupakan saham yang terpilih dalam pembentukan portofolio yang optimal. Saham yang terpilih yaitu terdiri dari saham PT. Pakuwon Jati Tbk (PWON) sebesar 0.62 dan pada saham PT. Suryamas Dutamakmur Tbk sebesar 0.38.

\section{Kesimpulan}

Berdasarkan perhitungan optimasi menggunakan metode NCP untuk memperoleh portofolio saham yang optimal, dihasilkan 2 saham terpilih dari keenam saham yang telah dianalisis. Saham-saham tersebut yaitu PT. Pakuwon Jati Tbk (PWON) dengan proporsi dana 0.62 dan PT. Suryamas Dutamakmur Tbk (SMDM) dengan proporsi dana 0.38 serta diperoleh nilai-nilai koefisien risiko, expected return, dan modal investasiyang terbentuk dari 2 saham terpilih yaitu saham PWON dan SMDM. Untuk koefisien risiko optimal sebesar 1, expected return maksimal sebesar 1\%, dan modal investasi minimal Rp.390,-.

Portofolio saham yang telah terbentuk dikatakan optimal karena disaat risiko $(\beta)$ bernilai 1 dimana saat $\beta=1$ menunjukan jika return pasar bergerak naik, return saham juga akan bergerak naik sama besarnya mengikuti return pasar. Harga suatu saham akan ditentukan 
oleh beta. Semakin besar koefisien beta suatu saham, investor akan memperoleh return yang semakin besar. Hal ini akan menunjukan bahwa harga saham akan memiliki hubungan positif dengan nilai betanya.

\section{Daftar Pustaka}

[1] Amiri, M., Ekhtiari, M., and Yazdani, M. 2011. "Nadir Compromise programming: A model for optimization of multi-objective portofolio problem". Expert System with Applications, Vol. 38, No. 6, pp 7222-7226.

[2] Fahmi, I. 2015. Manajemen Investasi. Edisi Kedua. Jakarta: Salemba Empat.

[3] Fajar, M. Y., dan Badruzzaman, F. H. 2005. "Program Tujuan Ganda dengan Metoda Goal Programming”. Jurnal Matematika, Vol. 4 No.1. Bandung: Universitas Islam Bandung.

[4] Fauziah, D. Suhaedi, D., dan Gunawan, G. 2016. "Program Linear Fuzzy dengan Koefisien dan Konstanta Kendala Bilangan Fuzzy". Prosiding Matematika. Bandung: Universitas Islam Bandung.

[5] Husnan, S. 2003. Dasar-Dasar Teori Portofolio. Edisi Ketiga. Yogyakarta: UPP AMP YKPN.

[6] Noviyanto, Wandi. 2016. "Perbandingan Nilai Optimal Portofolio Saham dengan Metode Compromise Programming dan Metode Nadir Compromise Programming". Skripsi. Jurusan Matematika, Universitas Udayana.

[7] Nurdiawan, W. Kurniati, E. dan Suhaedi, D. 2015. "Analisis Hubungan Return dan Risiko Suatu Investasi berdasarkan Fungsi Linier dengan Menggunakan Capital Asset Pricing Model”. Prosiding Matematika. Bandung: Universitas Islam Bandung.

[8] Reilly, F. K. and Brown, K. C. 2011. Investment Analysis \& Portofolio Management. USA: South-Western Cengage Learning.

[9] Suhaedi, D. 2009. "Optimasi Solusi Kompromi dengan Menggunakan Metode Vikor untuk Menyelesaikan Persoalan Pengambilan Keputusan”. Seminar Nasional Matematika. 